\title{
Review
}

\section{The functions of TRPP2 in the vascular system}

\author{
Juan DU ${ }^{1}$, Jie FU' ${ }^{1}$, Xian-ming XIA², Bing SHEN ${ }^{1, *}$ \\ ${ }^{1}$ Department of Physiology, School of Basic Medicine, Anhui Medical University, Hefei 230032, China; ${ }^{2}$ Department of Gastroenterology \\ and Hepatology, The Fourth Affiliated Hospital of Anhui Medical University, Hefei 230032, China
}

TRPP2 (polycystin-2, PC2 or PKD2), encoded by the PKD2 gene, is a non-selective cation channel with a large single channel conductance and high $\mathrm{Ca}^{2+}$ permeability. In cell membrane, TRPP2, along with polycystin-1, TRPV4 and TRPC1, functions as a mechanotransduction channel. In the endoplasmic reticulum, TRPP2 modulates intracellular $\mathrm{Ca}^{2+}$ release associated with IP 3 receptors and the ryanodine receptors. Noteworthily, TRPP2 is widely expressed in vascular endothelial and smooth muscle cells of all major vascular beds, and contributes to the regulation of vessel function. The mutation of the PKD2 gene is a major cause of autosomal dominant polycystic kidney disease (ADPKD), which is not only a common genetic disease of the kidney but also a systemic disorder associated with abnormalities in the vasculature; cardiovascular complications are the leading cause of mortality and morbidity in ADPKD patients. This review provides an overview of the current knowledge regarding the TRPP2 protein and its possible role in cardiovascular function and related diseases.

Keywords: TRPP2; polycystin-2; vascular smooth muscle cell; endothelial cell; hypertension; autosomal dominant polycystic kidney disease (ADPKD)

Acta Pharmacologica Sinica (2016) 37: 13-18; doi: 10.1038/aps.2015.126

\section{Introduction}

TRPP2 (transient receptor potential polycystic 2, previously known as polycystin-2, PC2, or PKD2) is a nonselective cation channel protein encoded by the PKD2 gene. It has a large single-channel conductance and high $\mathrm{Ca}^{2+}$ permeability ${ }^{[1-3]}$. The TRPP2 protein comprises 968 amino acids, which form six transmembrane segments ${ }^{[1]}$ with an endoplasmic reticulum (ER) retention signal in the C-terminal domain ${ }^{[4,5]}$, two cytosolic extremities including two EF-hands (residues 720-797) ${ }^{[6]}$, a coiled-coil domain (residues $828-895)^{[6-8]}$ and an acidic amino acid cluster (residues 798-827) ${ }^{[9,10]}$ (Figure 1). TRPP2 interacts with many proteins, primarily cytoskeletal components ${ }^{[11]}$. The acidic cluster can be recognized by phosphofurin acidic cluster sorting protein-1 (PACS-1) and PACS-2, and it regulates the trafficking of TRPP2 among the ER, the Golgi and the plasma membrane ${ }^{[9]}$. The coiled-coil domain contributes to homomeric assembly within TRPP2 or heteromeric assembly between TRPP2 and another TRPP family protein, polycystin- $1^{[7,12,13]}$. Four TRPP2 subunits assemble into a functional ion channel (Figure 1). N- and C-termini of the TRPP2 protein contain dimerization domains, which are important

\footnotetext{
* To whom correspondence should be addressed. E-mail shenbing@ahmu.edu.cn

Received 2015-09-14 Accepted 2015-11-02
}

components of TRPP2 channel assembly ${ }^{[14,15]}$. In addition to TRPP2, PKD2-like 1 (PKD2L1) and PKD2-like 2 (PKD2L2) are two other members of the TRPP subfamily of ion channels sharing structural homology with TRPP2 ${ }^{[16]}$. TRPP2 has been implicated in various cellular processes including mechanosensation, polarity, apoptosis, cellular proliferation, mating behavior and directed sperm movement ${ }^{[17]}$.

Mutation of the PKD2 gene is a major cause of autosomal dominant polycystic kidney disease (ADPKD), which is a common genetic disease of the kidney ${ }^{[18]}$. However, patients with ADPKD suffer from not only a defect in kidney function but also a systemic disorder associated with abnormalities in the vasculature, such as cerebral, intracranial, and aortic aneurysms and cardiac valvular dysfunction ${ }^{[19-21]}$. Therefore, cardiovascular complications are typically the leading cause of mortality and morbidity in ADPKD patients ${ }^{[22-26]}$. Evidence from the literature has shown that TRPP2 is widely expressed in the endothelial cells of mesenteric arteries ${ }^{[27]}$ and the smooth muscle cells of cerebral arteries ${ }^{[28,29]}$, the aorta ${ }^{[30-32]}$, and mesenteric arteries ${ }^{[31]}$, thus suggesting that TRPP2 may serve an important function in the cardiovascular system.

TRPP2's expression pattern and agonists and antagonists TRPP2 is expressed in various tissues including epithelial cells, vascular smooth muscle cells, endothelial cells, cardiac 


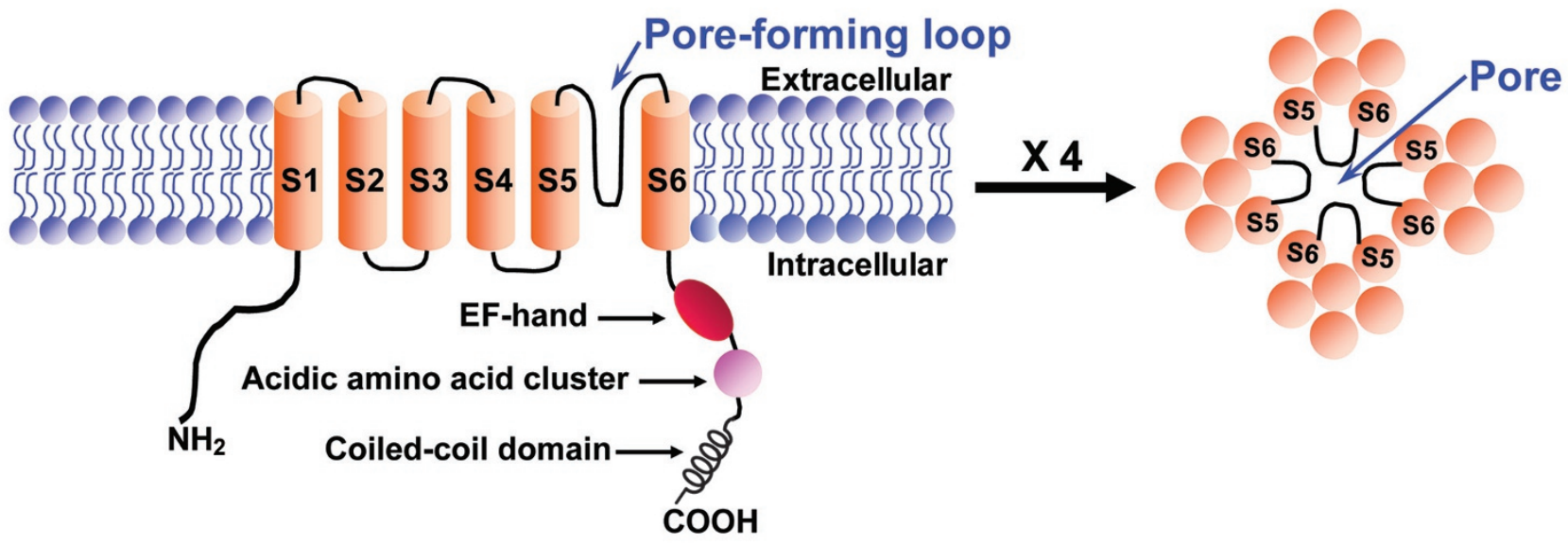

Figure 1. The structural features of a TRPP2 channel. A single TRPP2 subunit comprises six transmembrane segments (S1-S6) with a cationpermeable pore between S5 and S6. In the cytoplasmic C-terminus, there are EF-hands, a coiled-coil domain, and an acidic amino acid cluster. Four such units assemble into an ion channel.

myocytes, adrenal glands, and ovaries ${ }^{[33]}$. The subcellular localization of TRPP2 is dependent on its subsequent interaction with various trafficking proteins. TRPP2 contains an ER retention signal, which causes the protein to be retained in the ER compartment ${ }^{[4,5]}$. TRPP2 is most prominently localized to the ER, plasma membrane, primary cilia, mitotic spindles, and lamellipodia ${ }^{[5,34-41]}$. Numerous studies have indicated that transient receptor potential (TRP) isoforms have the ability to form homomultimeric or heteromultimeric channels with the same or other subfamilies. These new heteromultimeric channels typically have many novel biophysical properties, modes of activation, or simply more efficient trafficking of the ion conducting subunit to the plasma membrane ${ }^{[42]}$. To date, the literature has shown that the TRPP2 subunit might assemble into both homomeric and heteromeric complex channels with polycystin- $1^{[43,44]}, \mathrm{TRPC}^{[29,45-47]}, \mathrm{TRPC}^{[48]}{ }^{[4 R P C} 4^{[49]}$, TRPC5 $5^{[50]}$, TRPC $^{[48]}$ and TRPV4 ${ }^{[51-53]}$.

The pharmacology associated with TRPP2 is poorly understood. So far, identification of a specific chemical antagonist acting on TRPP2 is still lacking. To examine the physiological function of TRPP2, Nauli et al have designed a specific antibody targeting the part of the first extracellular loop of mouse TRPP2 (residues 278-428) and thereby inhibiting pore function $^{[34]}$. The authors found that inhibitory antibody completely prevented flow-induced $\mathrm{Ca}^{2+}$ influx into kidney cells, whereas a control antibody against the intracellular domain of TRPP2 (p96525) had no effect ${ }^{[34]}$. Amiloride, $\mathrm{La}^{3+}$, and $\mathrm{Gd}^{3+}$ have been proposed to be TRPP2 inhibitors, although they do not specifically inhibit TRPP2. In addition, TRPP2 is inhibited by cytoplasmic $\mathrm{pH}$ and is modulated by the holding potential due to its $\mathrm{H}^{+}$sensitive and voltage-dependent properties ${ }^{[54]}$. Abdi et al have reported that triptolide, an agonist of TRPP2, evokes TRPP2-mediated $\mathrm{Ca}^{2+}$ release from internal $\mathrm{Ca}^{2+}$ storage; however, the specificity of triptolide's action on TRPP2 is not well documented ${ }^{[28]}$. Therefore, the identification of the specific agonist and antagonist of TRPP2 should be a challenge for scientists in future studies.

\section{The function of TRPP2 in the regulation of intracellular} $\mathrm{Ca}^{2+}$ homeostasis

A debate exists with respect to the localization of TRPP2 in cells. Many studies have reported that TRPP2 located in the plasma membrane, along with polycystin-1, TRPV4 and TRPC1, bears a cationic current induced by mechanotransduction and is responsible for various physiological functions ${ }^{[27,34,43,51,55-57]}$. Other studies have shown that TRPP2 is expressed in the ER and either acts as a leak channel that lowers the $\mathrm{Ca}^{2+}$ concentration in the $\mathrm{ER}^{[58,59]}$ or acts in association with inositol 1,4,5-trisphosphate receptors $\left(\mathrm{IP}_{3} \mathrm{R}\right)$ and the ryanodine receptor $(\mathrm{RyR})$ in modulating intracellular $\mathrm{Ca}^{2+}$ concentration $\left(\left[\mathrm{Ca}^{2+}\right]_{\mathrm{i}}\right)$ homeostasis $^{[60-62]}$. A portion of the TRPP2 $\mathrm{N}$-terminus interacts with $\mathrm{RyR}$ and thus reduces RyR-mediated $\mathrm{Ca}^{2+}$ release ${ }^{[60]}$. Additionally, the acidic cluster in the TRPP2 C-terminal cytoplasmic tail may interact with a cluster of positively charged residues in the $\mathrm{IP}_{3} \mathrm{R} N$-terminal ligand-binding domain. Through this protein-protein interaction, the local cytosolic $\mathrm{Ca}^{2+}$ concentration increases. This concentration increase is initiated by $\mathrm{Ca}^{2+}$ release via $\mathrm{IP}_{3} \mathrm{R}$ and may activate TRPP2 and hence evoke further $\mathrm{Ca}^{2+}$ release ${ }^{[61,62]}$. The decreased $\mathrm{Ca}^{2+}$ concentration in the ER then evokes the oligomerization of stromal interacting molecule 1 (STIM1), which is a $\mathrm{Ca}^{2+}$ sensor in the $\mathrm{ER}^{[63,64]}$. Subsequently, oligomerized STIM1 activates a $\mathrm{Ca}^{2+}$-permeable ion channel, Orai1, in the plasma membrane ${ }^{[65]}$ and other storeoperated channels ${ }^{[66]}$, thus resulting in $\mathrm{Ca}^{2+}$ entry. This process is referred to as store-operated $\mathrm{Ca}^{2+}$ entry (SOCE). The purpose of SOCE is to mediate $\mathrm{Ca}^{2+}$ influx to refill $\mathrm{Ca}^{2+}$ stores after depletion.

Much like the $\mathrm{Ca}^{2+}$ release channels in the ER, TRPP2 channels may partially contribute to the transient $\left[\mathrm{Ca}^{2+}\right]_{i}$ increase and the intensity of SOCE. $\mathrm{Ca}^{2+}$ entry after depletion of intracellular $\mathrm{Ca}^{2+}$ stores by treatment with caffeine and thapsigargin is significantly lower in $\mathrm{TRPP}^{+/-}$mice than in wild type mice ${ }^{[32,58]}$. Cytoplasmic and ER Ca ${ }^{2+}$ levels and SOCE have been found to be decreased in TRPP2-defective cholangiocytes compared with wild type cells, whereas the expression levels 
of STIM1 and Orai1 were unchanged ${ }^{[67]}$.

\section{TRPP2's function in vascular smooth muscle cells}

TRPP2 is broadly expressed in vascular smooth muscle cells, where it optimizes muscle contractility ${ }^{[30,68]}$. Qian et al have found that, in vascular smooth muscle cells, TRPP2 is primarily located in the sarcoplasmic reticulum (SR) and in intracellular compartments, but polycystin-1 is located in the plasma membrane ${ }^{[32]}$. Despite these different subcellular localizations, the interaction between TRPP2 and polycystin-1 occurs across closely apposed plasmalemmal and SR membranes near the cell surface ${ }^{[32]}$. The interaction of TRPP2 and polycystin- 1 have also been found at dense plaques, which are sites of cytoskeletal/plasma membrane/extracellular matrix interaction that provide a mechanical and functional link to the regulation of the elastic and contractile tension of the stretched vesse ${ }^{[32,69,70]}$.

The SR $\mathrm{Ca}^{2+}$ store and basal $\left[\mathrm{Ca}^{2+}\right]_{\mathrm{i}}$ are decreased in $\mathrm{Pkd2} 2^{+-}$ arterial smooth muscle cells ${ }^{[58]}$. Furthermore, consistently with this finding, $P k d 2$ mutations severely decrease the contractility of the visceral smooth muscle cells in Drosophila, which can be restored by expressing wild type $P k d 2$ cDNA through a muscle-specific Gal4 driver ${ }^{[68]}$. Ren et al have also found that TRPP2 shRNA effectively suppresses TRPP2 protein expression as well as $\mathrm{a}_{1}$-adrenergic receptor agonist (phenylephrine)induced vasocontraction in the thoracic aorta and mesenteric arteries $^{[31]}$. However, $\mathrm{Pkd}^{+/}$arteries exhibit exaggerated vasocontraction and increased sensitivity to phenylephrine, which is caused by enhanced $\mathrm{Ca}^{2+}$-independent force generation and increased contractile protein expression ${ }^{[71]}$. In high salt intakeinduced hypertension, TRPP2 expression in vascular smooth muscle cells and phenylephrine-induced contractility of the aorta and mesenteric arteries are dramatically increased ${ }^{[31]}$. However, the weight of the aortic rings and the basal diameter of the mesenteric arteries is decreased ${ }^{[31]}$. Therefore, with the exception of blood vessel hypertrophy, the increase in the TRPP2 expression level in arterial smooth muscle cells appears to cause enhanced vasoconstriction induced by phenylephrine. One study has reported that in denuded aortic rings and mesenteric arteries, when $\mathrm{Ca}^{2+}$ stores are depleted through pretreatment with thapsigargin, no significant difference in the vasocontraction between TRPP2 and control shRNAtransduced rats was observed ${ }^{[31]}$. These findings indicate that TRPP2 located in the ER membrane may be more important than TRPP2 located in the plasma membrane in terms of agonist-induced vasocontraction. TRPP2 differentially regulates the myogenic response in different vascular beds. TRPP2 protein is primarily located in the plasma membrane of human and rat cerebral artery smooth muscle cells, in contrast to the expression observed in the ER or SR membrane in the mesenteric arteries and aorta ${ }^{[29,31,58]}$. TRPP2 knockdown by TRPP2 specific siRNA decreases swelling-activated cation currents in vascular smooth muscle cells and pressure-induced constriction in resistance-size cerebral arteries ${ }^{[29]}$. In addition, in vascular smooth muscle cells, an overabundance of free TRPP2 inhibits stretch-activated ion channels (SACs) through filamin A coupled to the actin cytoskeleton, but this inhibition can be reversed by coexpression with polycystin- $1^{[57]}$. This result indicates that the polycystin-1/TRPP2 ratio regulates SAC mechanosensitivity and pressure sensing.

\section{TRPP2's function in endothelial cells}

In the circulatory system, the shear stress generated from hemodynamic blood flow is a major physiological stimulus inducing endothelial cell-dependent vascular dilation ${ }^{[72]}$. In the process of shear stress-induced vessel dilation, a key early event is the flow-stimulated $\left[\mathrm{Ca}^{2+}\right]_{\mathrm{i}}$ increase in the vascular endothelial cells. TRPP2 is expressed in endothelial cells along with polycystin-1, TRPC1 and TRPV4, and it plays an important role as a mechanosensing $\mathrm{Ca}^{2+}$ channel. We have used a lentiviral construct carrying TRPP $2^{\mathrm{D} 511 \mathrm{~V}}$ (dead mutant) to explore the functional role of TRPP2 in flow-induced vascular dilation $^{[27]}$. Dilation was significantly reduced in the arteries isolated from lenti-TRPP $2^{\text {D511V }}$-treated rats compared with arteries from empty lentivector-treated rats, which suggests the participation of TRPP2 in flow-induced vascular dilation.

TRPP2 shows mechanosensitive properties when it associates with polycystin-1 (formerly TRPP1), thereby functioning as a mechano-sensor. However, TRPP2 may lose its mechanosensitive activity when it is expressed alone ${ }^{[3,34,57]}$. TRPP2 may owe its mechanosensitive properties to coupling with other TRP subunits, presumably TRPC1 and/or TRPV4 ${ }^{[27,52,73]}$. Knockdown of the TRPP2 protein significantly decreases the initial stretch-induced $\left[\mathrm{Ca}^{2+}\right]_{\mathrm{i}}$ increase, whereas TRPC1 knockdown significantly decreases the later $\left[\mathrm{Ca}^{2+}\right]_{\mathrm{i}}$ increase $^{[45]}$. However, the combined knockdown of TRPP2 and TRPC1 is necessary to significantly decrease the stretch-induced $\left[\mathrm{Ca}^{2+}\right]_{\mathrm{i}}$ changes ${ }^{[45]}$. These findings suggest that TRPP2 channels may substantially contribute to the $\left[\mathrm{Ca}^{2+}\right]_{\mathrm{i}}$ increase in the first few minutes after stretch stimulus.

TRPP2 may associate with TRPV4 and TRPC1, thus forming heteromultimeric channels mediating flow-induced $\mathrm{Ca}^{2+}$ influx in TRPV4, TRPC1, and TRPP2 co-overexpressing HEK293 cells and rat mesenteric artery endothelial cells ${ }^{[27]}$. In this crosssubfamily assembly of TRPs, TRPV4 is essential to the flowinduced response. However, the heteromultimeric channels may display different properties from those of the homomultimeric channels. Flow-induced $\mathrm{Ca}^{2+}$ increases are transient in HEK293 cells overexpressing TRPV4 alone but become sustained when TRPV4 is co-expressed with TRPP2 or TRPC1 ${ }^{[27]}$. PKG-mediated inhibition of TRPV4-TRPC1-TRPP2 channels might contribute to the transient nature of the flow-induced $\left[\mathrm{Ca}^{2+}\right]_{\mathrm{i}}$ increase in vascular endothelial cells ${ }^{[27]}$. Through this negative feedback mechanism, $\mathrm{Ca}^{2+}$ influx would stimulate a nitric oxide (NO)-cGMP-PKG signaling cascade and cause the inhibition of $\mathrm{Ca}^{2+}$ entry channels ${ }^{[27]}$.

Mechanical stress can quickly lead to the dysfunction of the microvessel endothelial cells, including the disruption of the blood-brain barrier (BBB $)^{[45]}$. Mechanical stress and $\left[\mathrm{Ca}^{2+}\right]_{\mathrm{i}}$ elevation can produce functional modification of the tight junction complex, which leads to barrier leakiness ${ }^{[74,75]}$. The mechanical stress delivered to the brain tissue during traumatic brain injury is associated with two ion channels: TRPP2 
and TRPC $1^{[45]}$. These channels appear to be largely responsible for the prolonged dynamics ${ }^{[45]}$.

An abnormal response to hyperemia and endotheliumdependent vasorelaxation has been found in ADPKD patients and in different animal models of ADPKD ${ }^{[20,21]}$. ADPKD patients display a reduction in endothelium-dependent vessel dilatation in conduit arteries during the increase of sustained blood flow, which is associated with the complete loss of $\mathrm{NO}$ release ${ }^{[76]}$. Karen et al have found that the aorta in an autosomal recessive ARPKD animal model had abnormal endothelium-dependent vascular reactivity, likely due to a primary defect in the endothelial cells that occurred prior to the changes in mean arterial pressure or renal function. However, the endothelium-independent relaxation, for example, that in smooth muscle cells, was not impaired ${ }^{[19]}$.

\section{TRPP2 in blood pressure regulation}

A portion $(10 \%-20 \%)$ of children with ADPKD presents with hypertension symptoms, and the majority of adults exhibit hypertension before any loss of kidney function has occurred $^{[77]}$. Hypertension relates to progressive kidney enlargement and is a significant independent risk factor for the progression toward end stage renal disease $\mathrm{e}^{[78,79]}$. The pathogenesis of hypertension in ADPKD is complex and dependent on many factors that influence each other. Defects in the primary cilia causing endothelial dysfunction and the activation of the renin-angiotensin-aldosterone system are central pathophysiologic explanations for the development of hypertension in $\mathrm{ADPKD}^{[80]}$. The treatment of hypertension effectively reduces cardiovascular mortality and may also slow the progression of kidney disease ${ }^{[81,82]}$.

Decreased or absent polycystin-1 or TRPP2 protein expression is associated with abnormal vascular structure and function. A $P k d 1$ (which encodes polycystin-1) /Pkd2 deficiency results in decreased NO levels and altered endothelial response to shear stress with the attenuation in vascular relaxation in ADPKD patients ${ }^{[20,21]}$.

Kocyigit et al have demonstrated that ADPKD patients with hypertension have low levels of endothelial nitric oxide synthase (eNOS) expression compared with patients without hypertension and that eNOS expression is an independent predictive factor of hypertension in the ADPKD population ${ }^{[83]}$. In addition, TRPP2 protein expression has been shown to be dramatically increased in the vascular smooth muscle cells of the thoracic aorta and mesenteric arteries in high salt intakeinduced hypertensive rats compared to age-controlled rats ${ }^{[31]}$.

\section{Conclusion and perspectives}

TRPP2 is widely expressed in the endothelial cells and smooth muscle cells of diverse vascular beds. Even dysfunctional mutation of TRPP2 causes severe renal dysfunction, and vascular complications are the primary reason for mortality and morbidity. Therefore, TRPP2 is considered to be an important target for modulating vascular function. However, the physiological and pathological functions of TRPP2, as well as their underlying molecular mechanisms in the vascular system, are still not completely understood. The conditional TRPP2 knockout model of the vascular system might be a powerful approach to address this issue. However, specific chemical agonists and antagonists of TRPP2 are largely lacking, thus hindering the elucidation of TRPP2's functional role in various tissues. Collaboration between researchers in various fields is needed for identifying the TRPP2-specific agonists and antagonists. These compounds will benefit both the investigation of physiological function and the development of therapeutic drugs in the future.

\section{Acknowledgements}

This work was supported by grants from the National Natural Science Foundation of China (№s 81570403, 81371284), the Outstanding Young Investigator of Anhui Medical University program, the Young Prominent Investigator Supporting Program from Anhui Medical University, and the Supporting Program for Excellent Young Talents in Universities of Anhui Province.

\section{References}

1 Mochizuki T, Wu G, Hayashi T, Xenophontos SL, Veldhuisen B, Saris $\mathrm{JJ}$, et al. PKD2, a gene for polycystic kidney disease that encodes an integral membrane protein. Science 1996; 272: 1339-42.

2 Delmas P, Padilla F, Osorio N, Coste B, Raoux M, Crest M. Polycystins, calcium signaling, and human diseases. Biochem Biophys Res Commun 2004; 322: 1374-83.

3 Giamarchi A, Padilla F, Coste B, Raoux M, Crest M, Honore E, et al. The versatile nature of the calcium-permeable cation channel TRPP2. EMBO Rep 2006; 7: 787-93.

4 Fu X, Wang Y, Schetle N, Gao H, Putz M, von Gersdorff G, et al. The subcellular localization of TRPP2 modulates its function. J Am Soc Nephrol 2008; 19: 1342-51.

5 Cai Y, Maeda Y, Cedzich A, Torres VE, Wu G, Hayashi T, et al. Identification and characterization of polycystin-2, the PKD2 gene product. J Biol Chem 1999; 274: 28557-65.

6 Petri ET, Celic A, Kennedy SD, Ehrlich BE, Boggon TJ, Hodsdon ME. Structure of the EF-hand domain of polycystin-2 suggests a mechanism for $\mathrm{Ca}^{2+}$-dependent regulation of polycystin-2 channel activity. Proc Natl Acad Sci U S A 2010; 107: 9176-81.

7 Yu Y, Ulbrich MH, Li MH, Buraei Z, Chen XZ, Ong AC, et al. Structural and molecular basis of the assembly of the TRPP2/PKD1 complex. Proc Natl Acad Sci U S A 2009; 106: 11558-63.

8 Celic A, Petri ET, Demeler B, Ehrlich BE, Boggon TJ. Domain mapping of the polycystin-2 C-terminal tail using de novo molecular modeling and biophysical analysis. J Biol Chem 2008; 283: 28305-12.

9 Kottgen M, Benzing T, Simmen T, Tauber R, Buchholz B, Feliciangeli $\mathrm{S}$, et al. Trafficking of TRPP2 by PACS proteins represents a novel mechanism of ion channel regulation. EMBO J 2005; 24: 705-16.

10 Sammels E, Devogelaere B, Mekahli D, Bultynck G, Missiaen L, Parys $\mathrm{JB}$, et al. Unraveling the role of polycystin-2/inositol 1,4,5-trisphosphate receptor interaction in Ca signaling. Commun Integr Biol 2010; 3: 530-2.

11 Chen XZ, Li Q, Wu Y, Liang G, Lara CJ, Cantiello HF. Submembraneous microtubule cytoskeleton: interaction of TRPP2 with the cell cytoskeleton. FEBS J 2008; 275: 4675-83.

12 Tsiokas L, Kim E, Arnould T, Sukhatme VP, Walz G. Homo- and heterodimeric interactions between the gene products of PKD1 and PKD2. Proc Natl Acad Sci U S A 1997; 94: 6965-70. 
13 Qian F, Germino FJ, Cai Y, Zhang X, Somlo S, Germino GG. PKD1 interacts with PKD2 through a probable coiled-coil domain. Nat Genet 1997; 16: 179-83.

14 Feng S, Okenka GM, Bai CX, Streets AJ, Newby L, DeChant BT, et al. Identification and functional characterization of an N-terminal oligomerization domain for polycystin-2. J Biol Chem 2008; 283: 28471-9.

15 Giamarchi A, Feng S, Rodat-Despoix L, Xu Y, Bubenshchikova E, Newby $\sqcup$, et al. A polycystin-2 (TRPP2) dimerization domain essential for the function of heteromeric polycystin complexes. EMBO J 2010; 29 : 1176-91.

16 Delmas P. Polycystins: polymodal receptor/ion-channel cellular sensors. Pflugers Arch 2005; 451: 264-76.

17 Kottgen M. TRPP2 and autosomal dominant polycystic kidney disease. Biochim Biophys Acta 2007; 1772: 836-50.

18 Gabow PA. Autosomal dominant polycystic kidney disease. Am J Kidney Dis 1993; 22: 511-2.

19 Peterson KM, Franchi F, Loeffler DL, Psaltis PJ, Harris PC, Lerman LO, et al. Endothelial dysfunction occurs prior to clinical evidence of polycystic kidney disease. Am J Nephrol 2013; 38: 233-40.

20 Wang D, Iversen J, Strandgaard S. Endothelium-dependent relaxation of small resistance vessels is impaired in patients with autosomal dominant polycystic kidney disease. J Am Soc Nephrol 2000; 11: 1371-6.

21 Wang D, Iversen J, Wilcox CS, Strandgaard S. Endothelial dysfunction and reduced nitric oxide in resistance arteries in autosomal-dominant polycystic kidney disease. Kidney Int 2003; 64: 1381-8.

22 Errasti P, Manrique J, Lavilla J, Rossich E, Hernandez A, Pujante D, et al. Autosomal-dominant polycystic kidney disease: high prevalence of graft loss for death-related malignancies and cardiovascular risk factors. Transplant Proc 2003; 35: 1717-9.

23 Alam A, Perrone RD. Left ventricular hypertrophy in ADPKD: changing demographics. Curr Hypertens Rev 2013; 9: 27-31.

24 Seker Kockara A, Kayatas M, Huzmeli C, Candan F, Gumus C. Interrupted aortic arch in an adult with polycystic kidney disease. Case Reports Med 2013; 2013: 4047-10.

25 Kubo S, Nakajima M, Fukuda K, Nobayashi M, Sakaki T, Aoki K, et al. A 4-year-old girl with autosomal dominant polycystic kidney disease complicated by a ruptured intracranial aneurysm. Eur J Pediatr 2004; 163: 675-7.

26 De Almeida EA, Prata MM. Hypertension in autosomal dominant polycystic kidney disease: observational study in 207 patients with a mean follow-up of 107 months. Rev Port Cardiol 2007; 26: 1173-82.

27 Du J, Ma X, Shen B, Huang Y, Birnbaumer L, Yao X. TRPV4, TRPC1, and TRPP2 assemble to form a flow-sensitive heteromeric channel. FASEB J 2014; 28: 4677-85.

28 Abdi A, Mazzocco C, Legeron FP, Yvert B, Macrez N, Morel JL. TRPP2 modulates ryanodine- and inositol-1,4,5-trisphosphate receptors-dependent Ca signals in opposite ways in cerebral arteries. Cell Calcium 2015; 58: 467-75.

29 Narayanan D, Bulley S, Leo MD, Burris SK, Gabrick KS, Boop FA, et al. Smooth muscle cell transient receptor potential polycystin-2 (TRPP2) channels contribute to the myogenic response in cerebral arteries. J Physiol 2013; 591: 5031-46.

30 Torres VE, Cai Y, Chen X, Wu GQ, Geng L, Cleghorn KA, et al. Vascular expression of polycystin-2. J Am Soc Nephrol 2001; 12: 1-9.

31 Zhao R, Zhou M, Li J, Wang X, Su K, Hu J, et al. Increased TRPP2 expression in vascular smooth muscle cells from high-salt intake hypertensive rats: the crucial role in vascular dysfunction. Mol Nutr Food Res 2015; 59: 365-72.

32 Qian Q, Li M, Cai Y, Ward CJ, Somlo S, Harris PC, et al. Analysis of the polycystins in aortic vascular smooth muscle cells. J Am Soc Nephrol
2003; 14: 2280-7.

33 Ong AC. Polycystin expression in the kidney and other tissues: complexity, consensus and controversy. Exp Nephrol 2000; 8: 208-14.

34 Nauli SM, Alenghat FJ, Luo Y, Williams E, Vassilev P, Li X, et al. Polycystins 1 and 2 mediate mechanosensation in the primary cilium of kidney cells. Nat Genet 2003; 33: 129-37.

35 Newby L, Streets AJ, Zhao Y, Harris PC, Ward CJ, Ong AC. Identification, characterization, and localization of a novel kidney polycystin1-polycystin-2 complex. J Biol Chem 2002; 277: 20763-73.

36 Yoder BK, Hou X, Guay-Woodford LM. The polycystic kidney disease proteins, polycystin-1, polycystin-2, polaris, and cystin, are co-localized in renal cilia. J Am Soc Nephrol 2002; 13: 2508-16.

37 Foggensteiner L, Bevan AP, Thomas R, Coleman N, Boulter C, Bradley J, et al. Cellular and subcellular distribution of polycystin-2, the protein product of the PKD2 gene. J Am Soc Nephrol 2000; 11: 814-27.

38 Rundle DR, Gorbsky G, Tsiokas L. PKD2 interacts and co-localizes with mDia1 to mitotic spindles of dividing cells: role of mDia1 IN PKD2 localization to mitotic spindles. J Biol Chem 2004; 279: 29728-39.

39 Witzgall R. Polycystin-2--an intracellular or plasma membrane channel? Naunyn-Schmiedeberg's Arch Pharmacol 2005; 371: 342-7.

40 Koulen P, Cai Y, Geng L, Maeda Y, Nishimura S, Witzgall R, et al. Polycystin-2 is an intracellular calcium release channel. Nat Cell Biol 2002; 4: 191-7.

41 Pazour GJ, San Agustin JT, Follit JA, Rosenbaum JL, Witman GB. Polycystin-2 localizes to kidney cilia and the ciliary level is elevated in orpk mice with polycystic kidney disease. Curr Biol 2002; 12: R378-80.

42 Venkatachalam K, Montell C. TRP channels. Ann Rev Biochem 2007; 76: 387-417.

43 Hanaoka K, Qian F, Boletta A, Bhunia AK, Piontek K, Tsiokas L, et al. Co-assembly of polycystin-1 and -2 produces unique cation-permeable currents. Nature 2000; 408: 990-4.

44 Zhu J, Yu Y, Ulbrich MH, Li MH, Isacoff EY, Honig B, et al. Structural model of the TRPP2/PKD1 C-terminal coiled-coil complex produced by a combined computational and experimental approach. Proc Natl Acad Sci U S A 2011; 108: 10133-8.

45 Berrout J, Jin M, O'Neil RG. Critical role of TRPP2 and TRPC1 channels in stretch-induced injury of blood-brain barrier endothelial cells. Brain Res 2012; 1436: 1-12.

46 Kobori T, Smith GD, Sandford R, Edwardson JM. The transient receptor potential channels TRPP2 and TRPC1 form a heterotetramer with a 2:2 stoichiometry and an alternating subunit arrangement. J Biol Chem 2009; 284: 35507-13.

47 Tsiokas L, Arnould T, Zhu C, Kim E, Walz G, Sukhatme VP. Specific association of the gene product of PKD2 with the TRPC1 channel. Proc Natl Acad Sci U S A 1999; 96: 3934-9.

48 Miyagi K, Kiyonaka S, Yamada K, Miki T, Mori E, Kato K, et al. A pathogenic $C$ terminus-truncated polycystin- 2 mutant enhances receptor-activated $\mathrm{Ca}^{2+}$ entry via association with TRPC3 and TRPC7. J Biol Chem 2009; 284: 34400-12.

49 Du J, Ding M, Sours-Brothers S, Graham S, Ma R. Mediation of angiotensin II-induced $\mathrm{Ca}^{2+}$ signaling by polycystin 2 in glomerular mesangial cells. Am J Physiol Renal Physiol 2008; 294: F909-18.

50 Sutton KA, Jungnickel MK, Ward CJ, Harris PC, Florman HM. Functional characterization of PKDREJ, a male germ cell-restricted polycystin. J Cell Physiol 2006; 209: 493-500.

51 Du J, Wong WY, Sun L, Huang Y, Yao X. Protein kinase G inhibits flowinduced $\mathrm{Ca}^{2+}$ entry into collecting duct cells. J Am Soc Nephrol 2012; 23: $1172-80$.

52 Kottgen M, Buchholz B, Garcia-Gonzalez MA, Kotsis F, Fu X, Doerken M, et al. TRPP2 and TRPV4 form a polymodal sensory channel complex. J Cell Biol 2008; 182: 437-47. 
53 Stewart AP, Smith GD, Sandford RN, Edwardson JM. Atomic force microscopy reveals the alternating subunit arrangement of the TRPP2TRPV4 heterotetramer. Biophys J 2010; 99: 790-7.

54 Gonzalez-Perrett S, Batelli M, Kim K, Essafi M, Timpanaro G, Moltabetti $\mathrm{N}$, et al. Voltage dependence and $\mathrm{pH}$ regulation of human polycystin-2-mediated cation channel activity. J Biol Chem 2002; 277 : 24959-66.

55 Delmas P. Polycystins: from mechanosensation to gene regulation. Cell 2004; 118: 145-8.

56 Heckel E, Boselli F, Roth S, Krudewig A, Belting HG, Charvin G, et al. Oscillatory flow modulates mechanosensitive klf2a expression through TRPV4 and TRPP2 during heart valve development. Curr Biol 2015; 25: $1354-61$.

57 Sharif-Naeini R, Folgering JH, Bichet D, Duprat F, Lauritzen I, Arhatte $M$, et al. Polycystin-1 and -2 dosage regulates pressure sensing. Cell 2009; 139: 587-96.

58 Qian Q, Hunter LW, Li M, Marin-Padilla M, Prakash YS, Somlo S, et al. Pkd2 haploinsufficiency alters intracellular calcium regulation in vascular smooth muscle cells. Human Mol Genet 2003; 12: 1875-80.

59 Wegierski T, Steffl D, Kopp C, Tauber R, Buchholz B, Nitschke R, et al. TRPP2 channels regulate apoptosis through the $\mathrm{Ca}^{2+}$ concentration in the endoplasmic reticulum. EMBO J 2009; 28: 490-9.

60 Anyatonwu Gl, Estrada M, Tian X, Somlo S, Ehrlich BE. Regulation of ryanodine receptor-dependent calcium signaling by polycystin-2. Proc Natl Acad Sci U S A 2007; 104: 6454-9.

61 Li Y, Wright JM, Qian F, Germino GG, Guggino WB. Polycystin 2 interacts with type I inositol 1,4,5-trisphosphate receptor to modulate intracellular $\mathrm{Ca}^{2+}$ signaling. J Biol Chem 2005; 280: 41298-306.

62 Sammels E, Devogelaere B, Mekahli D, Bultynck G, Missiaen L, Parys JB, et al. Polycystin-2 activation by inositol 1,4,5-trisphosphateinduced $\mathrm{Ca}^{2+}$ release requires its direct association with the inositol 1,4,5-trisphosphate receptor in a signaling microdomain. J Biol Chem 2010; 285: 18794-805.

63 Liou J, Kim ML, Heo WD, Jones JT, Myers JW, Ferrell JE Jr, et al. STIM is a $\mathrm{Ca}^{2+}$ sensor essential for $\mathrm{Ca}^{2+}$-store-depletion-triggered $\mathrm{Ca}^{2+}$ influx. Curr Biol 2005; 15: 1235-41.

64 Zhang SL, Yu Y, Roos J, Kozak JA, Deerinck TJ, Ellisman MH, et al. STIM1 is a $\mathrm{Ca}^{2+}$ sensor that activates CRAC channels and migrates from the $\mathrm{Ca}^{2+}$ store to the plasma membrane. Nature 2005; 437: 902-5.

65 Park CY, Hoover PJ, Mullins FM, Bachhawat P, Covington ED, Raunser S, et al. STIM1 clusters and activates CRAC channels via direct binding of a cytosolic domain to Orai1. Cell 2009; 136: 876-90.

66 Cheng KT, Ong HL, Liu X, Ambudkar IS. Contribution and regulation of TRPC channels in store-operated $\mathrm{Ca}^{2+}$ entry. Curr Topic Membr 2013; 71: 149-79.

67 Spirli C, Locatelli L, Fiorotto R, Morell CM, Fabris L, Pozzan T, et al. Altered store operated calcium entry increases cyclic 3',5'-adenosine monophosphate production and extracellular signal-regulated kinases 1 and 2 phosphorylation in polycystin-2-defective cholangiocytes. Hepatology 2012; 55: 856-68.
68 Gao Z, Joseph E, Ruden DM, Lu X. Drosophila Pkd2 is haploid-insufficient for mediating optimal smooth muscle contractility. J Biol Chem 2004; 279: 14225-31.

69 Davis EC. Smooth muscle cell to elastic lamina connections in developing mouse aorta. Role in aortic medial organization. Lab Invest 1993; 68: 89-99.

70 Davis EC. Immunolocalization of microfibril and microfibril-associated proteins in the subendothelial matrix of the developing mouse aorta. J Cell Sci 1994; 107: 727-36.

71 Qian Q, Hunter LW, Du H, Ren Q, Han Y, Sieck GC. Pkd2 ${ }^{+/}$vascular smooth muscles develop exaggerated vasocontraction in response to phenylephrine stimulation. J Am Soc Nephrol 2007; 18: 485-93.

72 Bevan JA, Kaley G, Rubanyi GM. Flow-dependent regulation of vascular function. New York: Oxford University Press; 1995.

73 Bai CX, Giamarchi A, Rodat-Despoix L, Padilla F, Downs T, Tsiokas L, et al. Formation of a new receptor-operated channel by heteromeric assembly of TRPP2 and TRPC1 subunits. EMBO Rep 2008; 9: 472-9.

74 Stuart RO, Sun A, Bush KT, Nigam SK. Dependence of epithelial intercellular junction biogenesis on thapsigargin-sensitive intracellular calcium stores. J Biol Chem 1996; 271: 13636-41.

75 Brown RC, Wu L, Hicks K, O'Neil RG. Regulation of blood-brain barrier permeability by transient receptor potential type $\mathrm{C}$ and type $\mathrm{V}$ calciumpermeable channels. Microcirculation 2008; 15: 359-71.

76 Lorthioir A, Joannides R, Remy-Jouet I, Freguin-Bouilland C, lacob M, Roche $\mathrm{C}$, et al. Polycystin deficiency induces dopamine-reversible alterations in flow-mediated dilatation and vascular nitric oxide release in humans. Kidney Int 2015; 87: 465-72.

77 Chapman AB, Stepniakowski K, Rahbari-Oskoui F. Hypertension in autosomal dominant polycystic kidney disease. Adv Chronic Kidney Dis 2010; 17: 153-63.

78 Gabow PA, Johnson AM, Kaehny WD, Kimberling WJ, Lezotte DC, Duley IT, et al. Factors affecting the progression of renal disease in autosomal-dominant polycystic kidney disease. Kidney Int 1992; 41: 1311-9.

79 Iglesias CG, Torres VE, Offord KP, Holley KE, Beard CM, Kurland LT. Epidemiology of adult polycystic kidney disease, Olmsted County, Minnesota: 1935-1980. Am J Kidney Dis 1983; 2: 630-9.

80 Rahbari-Oskoui F, Williams O, Chapman A. Mechanisms and management of hypertension in autosomal dominant polycystic kidney disease. Nephrol Dial Transplant 2014; 29: 2194-201.

81 Ecder T, Schrier RW. Hypertension in autosomal-dominant polycystic kidney disease: early occurrence and unique aspects. J Am Soc Nephrol 2001; 12: 194-200.

82 Patch C, Charlton J, Roderick PJ, Gulliford MC. Use of antihypertensive medications and mortality of patients with autosomal dominant polycystic kidney disease: a population-based study. Am J Kidney Dis 2011; 57: 856-62.

83 Kocyigit I, Taheri S, Sener EF, Unal A, Eroglu E, Ozturk F, et al. Endothelial nitric oxide synthase gene expression is associated with hypertension in autosomal dominant polycystic kidney disease. Cardiorenal Med 2014; 4: 269-79. 